\title{
The Effects of Acute Uterine Ischemia on Fetal Circulation $^{1}$
}

\author{
SANDRA A. CALVERT, JOHN A. WIDNESS, WILLIAM OH, AND BARBARA S. STONESTREET \\ Department of Pediatrics, Women and Infants Hospital of Rhode Island, Providence, Rhode Island 02905, and \\ Program in Medicine, Brown University, Providence, Rhode Island 02908
}

\begin{abstract}
The effects of acute maternal hemorrhage on uterine blood flow and fetal circulation were investigated in pregnant sheep. Nine chronically instrumented pregnant sheep (114-128 d gestation), phlebotomized from the iliac artery at the point of origin of the uterine artery, were studied at baseline, after acute hemorrhage, and immediately and two $h$ after replacement of the blood. Maternal hemorrhage caused a reduction in uterine blood flow as well as both fetal hypoxemia and acidemia. Changes in fetal organ blood flow measured by radionuclide-labeled microspheres showed that blood flow to the brain, heart, and adrenal glands increased $(p<0.05)$, whereas blood flow to the other major organs did not change significantly. Rapid replacement of blood restored all parameters to baseline values. We conclude that acute maternal hemorrhage causes a reduction in uterine blood flow, fetal hypoxemia, and acidemia with a secondary increase in blood flow to the high priority organs. Rapid replacement of blood reverses these effects. (Pediatr Res 27: 552-556, 1990)
\end{abstract}

Abruptio placenta and placenta previa are common problems in obstetrics. These maternal complications are associated with increased perinatal morbidity and mortality $(1-4)$. Recently, two studies $(1,4)$ showed that maternal bleeding in the last trimester of pregnancy and/or uteroplacental abruption at the time of delivery were associated with an increased incidence of periventricular leukomalacia in the neonate. Uteroplacental bleeding or separation of the placenta could result in a reduction in uteroplacental perfusion with a consequent decrease in oxygen delivery to the fetus. In addition, loss of maternal blood from the uteroplacental circulation may result in a decrease in the $\mathrm{Hb}$ content and oxygen carrying capacity of the blood in the uteroplacental circulation. The combination of decreased uteroplacental perfusion and oxygen carrying capacity results in a reduction in oxygen delivery to the fetus and fetal hypoxemia. The latter will invoke fetal circulatory adjustments including a redistribution in fetal combined ventricular output to protect the high priority organs at the expense of low priority organs (5-7). Similar fetal circulatory changes take place when umbilical blood flow is reduced $(8-10)$. To our knowledge, the fetal circulatory changes under conditions of combined reductions in uterine perfusion and oxygen carrying capacity have not been investigated in a chronically instrumented fetal sheep.

Brinkman et al. (11) investigated the effects of maternal hypovolemic shock in the acute sheep preparation but their animals were anesthetized with phenobarbital, which is known to modify

Received May 30, 1989; accepted February 7, 1990.

Reprints: Barbara S. Stonestreet, M.D., Women \& Infants Hospital, Department of Pediatrics, 101 Dudley Street, Providence, RI 02905.

Supported in part by the Perinatal Biology Training Grant \#T32 HDO7232-06.

'Presented in part at the Society for Gynecologic Investigation March 1989 Meeting in San Diego, California. the response to hemorrhage (12), and they did not study changes in fetal organ blood flow. Our study investigated the effects of acute hemorrhage at the origin of the uterine artery on fetal oxygenation and organ blood flow in a chronically instrumented fetal sheep.

\section{MATERIALS AND METHODS}

The study was approved by our institutional animal review board. Nine pregnant mixed breed ewes with singleton fetuses were surgically prepared at 114-128 d of gestation. They were fasted $24 \mathrm{~h}$ before surgery. The ewes were intubated under ketamine anesthesia, and anesthesia was maintained with 0.75 $2.0 \%$ halothane during surgery. All animals were ventilated using $100 \%$ oxygen.

With the ewe in the left lateral position, the uterus was exposed through a midline abdominal incision. Fetal hind limbs were exteriorized and, after instilling local anesthesia (Lidocaine $\mathrm{HCl}$ ) into the site of the skin incision, polyvinyl catheters (inner diameter, $0.86 \mathrm{~mm}$; outer diameter $1.32 \mathrm{~mm}$ ) were inserted into both pedal arteries and one pedal vein and passed centrally into the descending aorta and inferior vena cava respectively. The fetal neck was then exposed through a second uterine incision and a polyvinyl catheter (inner diameter $1.20 \mathrm{~mm}$; outer diameter $1.78 \mathrm{~mm}$ ) inserted into the carotid artery. The fetus was returned to the uterus and a catheter was placed in the amniotic fluid cavity. Amniotic fluid lost during surgery was replaced with warmed $0.9 \% \mathrm{NaCl}$ solution; both uterine incisions were sutured and ampicillin (200 mg) was added to the amniotic fluid. Through an incision on the right flank of the ewe, an electromagnetic flow transducer $(4.5,5.0$ or $5.5 \mathrm{~mm})$ that had been precalibrated in vitro (13) was then placed around the right uterine artery, just distal to the point of branching of the common uterine artery. The branch of the uterine artery serving the gluteal muscles, which originates just distal to the point of placement of the flow probe, was tied off before closure of the wound. A polyvinyl catheter (inner diameter, $0.86 \mathrm{~mm}$; outer diameter, $1.32 \mathrm{~mm}$ ) was then placed into the descending aorta of the ewe via the femoral artery. An additional large bore catheter (inner diameter, $2.0 \mathrm{~mm}$; outer diameter, $4.0 \mathrm{~mm}$ ) was placed in the right femoral artery and advanced approximately $25 \mathrm{~cm}$ so that the proximal end of the catheter was positioned in the iliac artery just proximal to the branching of the uterine arteries. All catheters and the flow transducer cable were passed through the abdominal wall onto the flank of the ewe, where they were protected by a cloth pouch sutured to the skin. The catheters were filled with heparinized saline solution. On the day of surgery and for $3 \mathrm{~d}$ postoperatively, the ewe received $1 \mathrm{gm}$ of ampicillin and $60 \mathrm{mg}$ of gentamicin daily by an intramuscular route.

Experimental protocol. Studies were performed on the 4 th to 7 th postoperative $\mathrm{d}$ and at $117-135 \mathrm{~d}$ of gestation, while the ewe was supported by a sling with free access to alfalfa pellets and water. Fetal arterial pH $\geq 7.30$ and $\mathrm{PO}_{2} \geq 15 \mathrm{~mm} \mathrm{Hg}$ at $37^{\circ} \mathrm{C}$ were minimum criteria for the initiation of the studies. Each 
study consisted of five series of measurements. These measurements included maternal and fetal heart rate and blood pressure, uterine blood flow, maternal and fetal arterial blood gases, $\mathrm{pH}$, $\mathrm{Hb}$ concentration, hematocrit and percentage oxygen saturation, fetal organ blood flow, and combined ventricular output. Fetal arterial blood samples were obtained from the lower abdominal aorta. After baseline determinations, the ewe was hemorrhaged through the large bore catheter placed in the iliac artery until the maternal blood pressure was approximately $60 \%$ of the control value and then the measurements were repeated. Bleeding was then continued to achieve a new reduced blood pressure level. After these two hemorrhage measurements, all blood that had been removed was returned to the ewe as rapidly as possible and the 4 th series of measurements obtained. The ewe was allowed to stand for $2 \mathrm{~h}$ and then final measurements made. At the end of the experiment, the ewe and fetal lamb were killed (T61, Hoechst-Roussel Agri-Vet, Summerville, NJ). The uterus and its contents were removed and an autopsy performed immediately on the fetus. The positions of the catheters were verified and whole organs were removed, individually weighed and placed in in $10 \%$ formalin until carbonization. Fetal brain was separated from the spinal cord at the level of the first cervical vertebrae and placed in formalin.

Methodology. Fetal organ blood flow and fetal combined ventricular output (with an exception of pulmonary blood flow) were measured with microspheres $(15 \pm 5 \mu \mathrm{m})$ labeled with one of six randomly assigned radionuclides: ${ }^{51} \mathrm{Cr},{ }^{113} \mathrm{Sn},{ }^{46} \mathrm{Sc},{ }^{95} \mathrm{Nb}$, ${ }^{57} \mathrm{Co}$, and ${ }^{103} \mathrm{Ru}$ (New England, Inc., Boston, MA) using previously established techniques (14). Approximately $1 \times 10^{6}$ microspheres suspended in $0.4 \mathrm{~mL}$ of $10 \%$ dextran and $0.01 \%$ Tween were injected into the inferior vena cava, and reference samples withdrawn from the carotid artery and lower abdominal aorta. After each reference blood withdrawal, the volume of blood removed from the fetus was replaced with blood from a donor fetus of a similar gestational age. The fetal organs, except the brain, were individually carbonized at $275^{\circ} \mathrm{F}$ for $72-96 \mathrm{~h}$. Ash so obtained was packed in glass vials and the small organs diluted with cold carbon to a height of $3 \mathrm{~cm}$. The brain was divided into sections representing cerebrum, cerebellum, pons, and medulla that were placed in counting vials to a height of $3 \mathrm{~cm}$. Blood, carbonized specimen, and brain sections were counted in a welltype gamma scintillation spectrometer [Tracor Analytic sample changer 1185, (Elk Grove Village, IL) interfaced with a multichannel analyzer, 8192 Channel series 40 processor (Canberra Industries, Meridian, CT)]. Blood flow data were generated with a Digital PdP-11/34 counter system (Digital Equipment, Maynard, MA), which corrected for isotope spillover and decay. Blood flows were calculated using the following equation (14):

blood flow $(\mathrm{mL} / \mathrm{min})=\frac{\text { tissue counts } / \mathrm{min}}{\text { reference blood sample counts } / \mathrm{min}}$

$\times$ rate of withdrawal of reference blood sample

All specimens had sufficient microspheres to ensure an accuracy of $\pm 5 \%$. Paired samples of kidneys and brain (data not shown) documented the absence of streaming. Combined ventricular output was calculated from the summation of blood flow to the individual organs and the carcass. Fetal and maternal blood gases were measured using a Corning Blood Gas Analyzer (168 Corning Scientific Instrument, Medford, MA) at $37^{\circ} \mathrm{C}$. Because the body temperature of the pregnant ewe is $39.5^{\circ} \mathrm{C}$ and the oxygen dissociation curve with $\mathrm{Hb}$ is temperature-dependent, our values are lower than those expected under physiologic conditions. $\mathrm{Hb}$ and oxygen saturation were measured using a hemoximeter (Radiometer, Copenhagen, Denmark) and hematocrits were measured using a microhematocrit method. Blood $\mathrm{O}_{2}$ content was calculated as the product of $\mathrm{O}_{2}$ saturation, $\mathrm{Hb}$ concentration and a $\mathrm{Hb}$ binding capacity of $1.36 \mathrm{~mL} \cdot \mathrm{dL}^{-1}$. Maternal and fetal heart rate and arterial pressure were monitored continuously from the lower abdominal aorta catheters of the ewe and fetus, respectively, using pressure transducers (Hewlett-Packard, model $1280 \mathrm{C}$, Lexington, MA) and recorded on a Hewlett-Packard polygraph (7758B series). Amniotic fluid pressure was similarly monitored and used as zero reference for fetal arterial pressure. Uterine blood flow was measured via a SP2202 electromagnetic flow meter (Gould Inc., Cardiovascular Products Division, Oxnard, CA) connected to the Hewlett-Packard polygraph.

Data analysis. All data were analyzed using a two-way analysis of variance for repeated measures. If a significant difference was found, the Dunnett's test was used to compare the means to the baseline values. All values were expressed as mean $\pm \mathrm{SD} ; p<$ 0.05 was considered statistically significant.

\section{RESULTS}

Figure 1 shows the changes in maternal blood pressure $(n=$ 9) and uterine blood flow $(n=4)$ through the right uterine artery during maternal hemorrhage and the subsequent recovery periods. Because of flow probe dislodgment between the time of surgery and the day of study, uterine blood flow was determined in only four animals. After the initial hemorrhage, the mean blood pressure was decreased to $61 \%$ of the baseline values and, after the second hemorrhage, to a mean of $57 \%$ of baseline values. The mean volume of blood withdrawn and duration of hemorrhage were 1072 (range 596-1489) and $462 \mathrm{~mL}$ (range 01087 ) and 20 (range $11-45$ ) and 10 (range 0-30) min, respectively, for the initial and second hemorrhage periods. After blood replacement (recovery periods), the maternal blood pressure returned to baseline values and was unchanged during the final $2 \mathrm{~h}$ of study. Right uterine arterial blood flow decreased significantly with decreasing blood pressure and then returned to baseline values after blood replacement. Table 1 shows that throughout the study there were no significant changes in maternal heart rate, $\mathrm{Hb}$ concentration, hematocrit, and blood gas parameters except for an increase in base excess above baseline at the end of recovery period. Throughout the experiment there were no significant changes in fetal blood pressure and heart rate (Table 2). However, fetal arterial $\mathrm{PaO}_{2}, \mathrm{O}_{2}$ saturation, and $\mathrm{O}_{2}$ content were all reduced significantly after the initial hemorrhage. After the second hemorrhage, these parameters were reduced further. After replacement of the maternal blood, all three parameters returned to baseline values. During the second hemorrhage period, the fetuses developed a combined respiratory and metabolic acidosis from which they recovered, but not until the end of the experiment. As shown in Figure 2, hemorrhage caused a significant increase in blood flow to the fetal adrenal glands, heart, and brain, which reverted to baseline values following replacement of blood. Figure 3 shows that the changes in

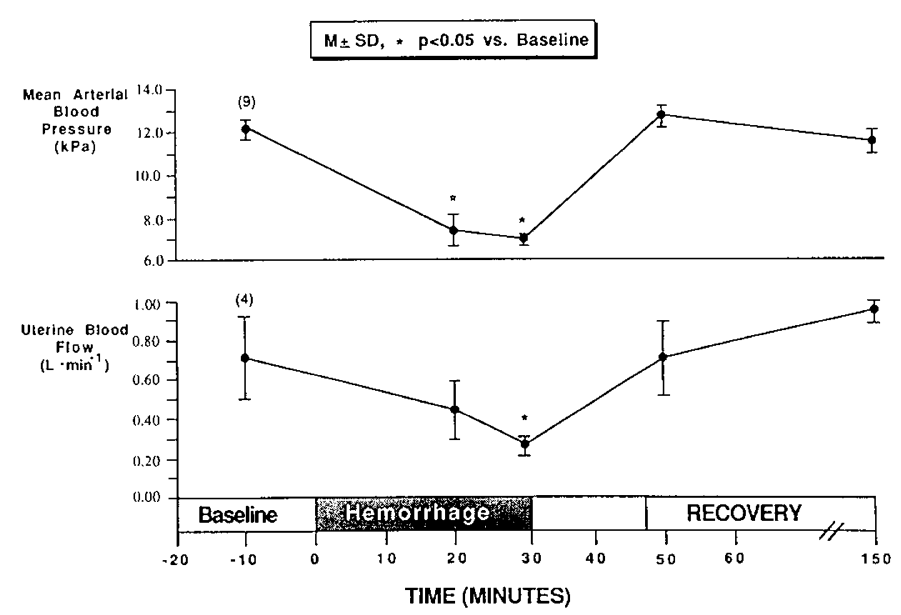

Fig. 1. Changes in maternal blood pressure $(n=9)$ and right uterine artery blood flow $(n=4)$ during maternal hemorrhage and after replacement of blood. 
Table 1. Maternal heart rate, $\mathrm{Hb}$, hematocrit, $\mathrm{pH}, \mathrm{PaCO}_{2}, \mathrm{PaO}_{2}$, base excess, $\mathrm{O}_{2}$ saturation, and $\mathrm{O}_{2}$ content after hemorrhage and recovery (mean $\pm S D, n=9$ )

\begin{tabular}{|c|c|c|c|c|c|}
\hline & \multicolumn{5}{|c|}{ Period } \\
\hline & \multirow{2}{*}{$\begin{array}{l}\text { Baseline } \\
-10 \mathrm{~min}\end{array}$} & \multicolumn{2}{|c|}{ Hemorrhage } & \multicolumn{2}{|c|}{ Recovery } \\
\hline & & $20 \mathrm{~min}$ & $30 \mathrm{~min}$ & $50 \mathrm{~min}$ & $150 \mathrm{~min}$ \\
\hline Heart rate (beats. $\min ^{-1}$ ) & $94.0 \pm 27.0$ & $89.0 \pm 40.0$ & $93.0 \pm 40.0$ & $103.0 \pm 26.0$ & $79.0 \pm 13.0$ \\
\hline $\mathrm{Hb}\left(\mathrm{g} \cdot \mathrm{L}^{-1}\right)$ & $92.0 \pm 5.0$ & $102.0 \pm 9.0$ & $92.0 \pm 10.0$ & $85.0 \pm 7.0$ & $93.0 \pm 10.0$ \\
\hline Hematocrit & $0.27 \pm 0.02$ & $0.29 \pm 0.04$ & $0.27 \pm 0.03$ & $0.25 \pm 0.01$ & $0.27 \pm 0.03$ \\
\hline $\mathrm{pH}$ & $7.45 \pm 0.04$ & $7.45 \pm 0.08$ & $7.47 \pm 0.10$ & $7.44 \pm 0.06$ & $7.48 \pm 0.06$ \\
\hline $\mathrm{PaCO}_{2}(\mathrm{kPa})$ & $4.66 \pm 0.27$ & $4.66 \pm 0.93$ & $4.26 \pm 1.20$ & $4.80 \pm 0.53$ & $4.80 \pm 0.53$ \\
\hline $\mathrm{PaO}_{2}(\mathrm{kPa})$ & $94.0 \pm 19.0$ & $89.0 \pm 29.0$ & $96.0 \pm 29.0$ & $97.0 \pm 19.0$ & $96.0 \pm 23.0$ \\
\hline $\mathrm{BE}\left(\mathrm{mmol} \cdot \mathrm{L}^{-1}\right)$ & $1.9 \pm 2.3$ & $1.5 \pm 3.1$ & $0.7 \pm 3.2$ & $1.3 \pm 3.1$ & $3.6 \pm 2.6^{*}$ \\
\hline $\mathrm{O}_{2}$ saturation (\%) & $93.7 \pm 10.0$ & $89.4 \pm 22.2$ & $89.4 \pm 24.3$ & $93.5 \pm 10.7$ & $93.6 \pm 10.7$ \\
\hline $\mathrm{O}_{2}$ content $\left(\mathrm{mL} \cdot \mathrm{dL}^{-1}\right)$ & $11.8 \pm 1.4$ & $12.4 \pm 3.4$ & $11.3 \pm 3.5$ & $10.8 \pm 1.3$ & $11.9 \pm 2.2$ \\
\hline
\end{tabular}

$* p<0.05$ vs baseline.

Table 2. Fetal blood pressure, heart rate, $\mathrm{pH}, \mathrm{PaCO}_{2}, \mathrm{PaO}_{2}$, base excess, $\mathrm{O}_{2}$ saturation, and $\mathrm{O}_{2}$ content after maternal hemorrhage and recovery (mean $\pm S D, n=9$ )

\begin{tabular}{|c|c|c|c|c|c|}
\hline & \multicolumn{5}{|c|}{ Period } \\
\hline & \multirow{2}{*}{$\begin{array}{l}\text { Baseline } \\
-10 \mathrm{~min}\end{array}$} & \multicolumn{2}{|c|}{ Hemorrhage } & \multicolumn{2}{|c|}{ Recovery } \\
\hline & & $20 \mathrm{~min}$ & $30 \mathrm{~min}$ & $50 \mathrm{~min}$ & $150 \min$ \\
\hline Blood pressure $(\mathrm{kPa})$ & $6.1 \pm 1.1$ & $6.5 \pm 1.1$ & $6.0 \pm 1.5$ & $6.0 \pm 1.5$ & $5.9 \pm 1.2$ \\
\hline Heart rate (beats. $\min ^{-1}$ ) & $186.0 \pm 32.0$ & $160.0 \pm 40.0$ & $186.0 \pm 34.0$ & $185.0 \pm 32.0$ & $200.0 \pm 40.0$ \\
\hline $\mathrm{pH}$ & $7.34 \pm 0.05$ & $7.28 \pm 0.13$ & $7.17 \pm 0.23^{*}$ & $7.19 \pm 0.14^{*}$ & $7.28 \pm 0.66$ \\
\hline $\mathrm{PaCO}_{2}(\mathrm{kPa})$ & $6.40 \pm 0.40$ & $7.33 \pm 1.60$ & $7.73 \pm 1.73$ & $7.20 \pm 1.07$ & $6.80 \pm 0.53$ \\
\hline $\mathrm{PaO}_{2}(\mathrm{kPa})$ & $2.27 \pm 0.27$ & $1.87 \pm 0.53$ & $1.60 \pm 0.27$ & $2.40 \pm 0.40$ & $2.27 \pm 0.27$ \\
\hline $\mathrm{BE}\left(\mathrm{mmol} \cdot \mathrm{L}^{-1}\right)$ & $0.5 \pm 3.4$ & $-2.9 \pm 5.0$ & $-6.5 \pm 7.7^{*}$ & $-8.5 \pm 7.3^{*}$ & $-4.5 \pm 7.2$ \\
\hline $\mathrm{O}_{2}$ saturation $(\%)$ & $54.4 \pm 7.0$ & $35.7 \pm 15.3^{*}$ & $25.5 \pm 8.6^{*}$ & $48.5 \pm 13.2$ & $50.1 \pm 10.9$ \\
\hline $\mathrm{O}_{2}$ content $\left(\mathrm{mL} \cdot \mathrm{dL}^{-1}\right)$ & $7.7 \pm 1.2$ & $5.3 \pm 2.2^{*}$ & $3.9 \pm 1.2^{*}$ & $7.3 \pm 2.2$ & $7.5 \pm 2.1$ \\
\hline
\end{tabular}

$* p<0.05$ vs baseline.

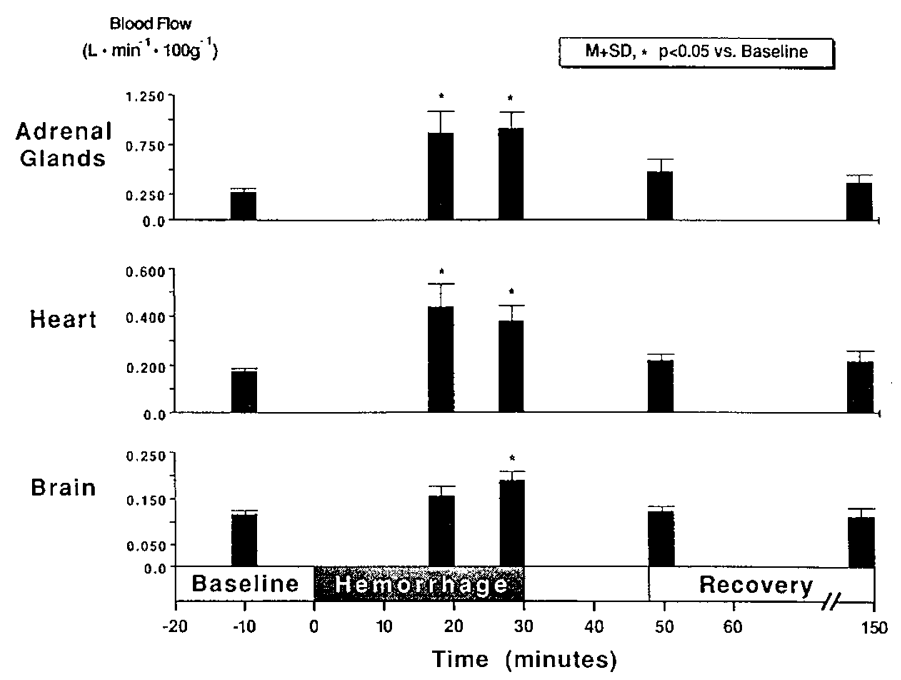

Fig. 2. Changes in fetal blood flow to adrenal glands, heart, and brain during maternal hemorrhage and after replacement of blood, $(n=9)$.

cerebral blood flow were reflected in all regions of the brain. Table 3 shows that there were no significant changes in blood flow to the fetal kidneys, gastrointestinal tract, or carcass during the hemorrhage period, whereas blood flow to the spleen was significantly lower than baseline values after the first hemorrhage. Throughout the study period, there were no significant changes in either blood flow to the placenta or the combined ventricular output. Furthermore, the changes in blood flow to the various organs were paralleled by changes in the percent of the fetal combined ventricular output distributed to the various fetal organs (Table 4).

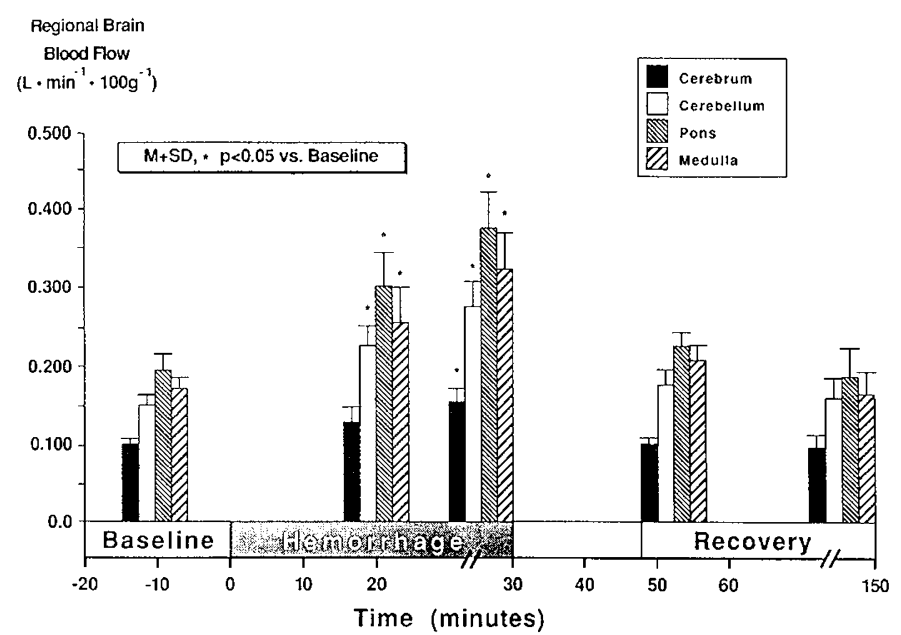

Fig. 3. Changes in blood flow to fetal cerebrum, cerebellum, pons, and medulla during maternal hemorrhage and after replacement of blood, $(n=9)$.

\section{DISCUSSION}

This study investigated the effects of acute maternal hemorrhage on fetal circulation in chronically catheterized fetal sheep. Uterine blood flow was reduced by maternal bleeding from the iliac artery at the origin of the uterine artery. Our experimental end point for hemorrhage was a reduction in maternal blood pressure, which will cause a decrease in uterine perfusion pressure. Because in the latter part of pregnancy the uterine arteries are nearly maximally dilated and cannot dilate further in response to a reduction in uterine perfusion pressure (15) and uterine blood flow is proportional to perfusion pressure (16), a 
Table 3. Fetal organ blood flow, placental flow, and fetal combined ventricular output after maternal hemorrhage and recovery, (mean $\pm S D, n=9$ )*

\begin{tabular}{|c|c|c|c|c|c|}
\hline & \multicolumn{5}{|c|}{ Period } \\
\hline & \multirow{2}{*}{$\begin{array}{l}\text { Baseline } \\
-10 \mathrm{~min}\end{array}$} & \multicolumn{2}{|c|}{ Hemorrhage } & \multicolumn{2}{|c|}{ Recovery } \\
\hline & & $20 \mathrm{~min}$ & $30 \mathrm{~min}$ & $50 \min$ & $150 \mathrm{~min}$ \\
\hline Spleen & $0.38 \pm 0.17$ & $0.16 \pm 0.13 \dagger$ & $0.22 \pm 0.16$ & $0.34 \pm 0.19$ & $0.31 \pm 0.14$ \\
\hline Kidneys & $0.14 \pm 0.07$ & $0.11 \pm 0.06$ & $0.11 \pm 0.04$ & $0.15 \pm 0.05$ & $0.17 \pm 0.04$ \\
\hline Gastrointestinal tract & $0.06 \pm 0.03$ & $0.06 \pm 0.04$ & $0.06 \pm 0.04$ & $0.08 \pm 0.03$ & $0.07 \pm 0.03$ \\
\hline Carcass & $0.02 \pm 0.01$ & $0.02 \pm 0.01$ & $0.02 \pm 0.01$ & $0.02 \pm 0.01$ & $0.02 \pm 0.01$ \\
\hline Placenta & $0.22 \pm 0.07$ & $0.18 \pm 0.06$ & $0.19 \pm 0.07$ & $0.19 \pm 0.06$ & $0.20 \pm 0.05$ \\
\hline $\mathrm{CVO}$ & $0.55 \pm 0.02$ & $0.48 \pm 0.16$ & $0.56 \pm 0.35$ & $0.47 \pm 0.09$ & $0.47 \pm 0.11$ \\
\hline
\end{tabular}

* Fetal organ blood flow $=\mathrm{L} \cdot \mathrm{min}^{-1} \cdot 100 \mathrm{~g}^{-1}$, placental blood flow and combined ventricular output $(\mathrm{CVO})=\mathrm{L} \cdot \mathrm{min}^{-1} \cdot \mathrm{kg}^{-1}$.

$\uparrow p<0.05$ vs baseline.

Table 4. Percent of fetal combined ventricular output distributed to fetal organs and placenta after maternal hemorrhage and recovery (mean $\pm S D, n=9$ )

\begin{tabular}{|c|c|c|c|c|c|}
\hline & \multicolumn{5}{|c|}{ Period } \\
\hline & \multirow{2}{*}{$\begin{array}{l}\text { Baseline } \\
-10 \mathrm{~min}\end{array}$} & \multicolumn{2}{|c|}{ Hemorrhage } & \multicolumn{2}{|c|}{ Recovery } \\
\hline & & $20 \min$ & $30 \mathrm{~min}$ & $50 \mathrm{~min}$ & $150 \mathrm{~min}$ \\
\hline Brain & $3.22 \pm 1.24$ & $5.04 \pm 3.10$ & $5.48 \pm 2.43^{*}$ & $3.66 \pm 1.12$ & $3.64 \pm 1.82$ \\
\hline Heart & $2.47 \pm 0.60$ & $7.49 \pm 5.75^{*}$ & $6.24 \pm 3.46^{*}$ & $3.87 \pm 1.80$ & $3.84 \pm 2.09$ \\
\hline Adrenal glands & $0.07 \pm 0.04$ & $0.28 \pm 0.25^{*}$ & $0.27 \pm 0.19^{*}$ & $0.14 \pm 0.15$ & $0.13 \pm 0.07$ \\
\hline Spleen & $1.51 \pm 0.74$ & $0.85 \pm 0.76^{*}$ & $1.00 \pm 0.80$ & $1.45 \pm 0.91$ & $1.33 \pm 0.69$ \\
\hline Kidneys & $2.16 \pm 0.94$ & $2.06 \pm 1.41$ & $2.04 \pm 1.12$ & $2.64 \pm 1.04$ & $2.40 \pm 0.91$ \\
\hline Gastrointestinal tract & $3.70 \pm 4.08$ & $4.08 \pm 3.11$ & $4.60 \pm 3.18$ & $6.02 \pm 2.46^{*}$ & $4.34 \pm 1.45$ \\
\hline Carcass & $33.28 \pm 11.88$ & $29.94 \pm 14.55$ & $27.80 \pm 12.53$ & $35.44 \pm 8.40$ & $37.71 \pm 6.84$ \\
\hline Placenta & $39.60 \pm 5.90$ & $37.70 \pm 14.40$ & $40.30 \pm 16.10$ & $39.50 \pm 10.30$ & $42.30 \pm 6.90$ \\
\hline
\end{tabular}

${ }^{*} p<0.05$ vs baseline.

decrease in uterine perfusion pressure will result in a decrease in uterine blood flow. Furthermore, because the uterine vascular bed participates in the generalized vasoconstrictive response to maternal hemorrhage (16), the decrease in maternal blood pressure causes vasoconstriction of the uterine arteries, thereby diverting available blood to the central circulation. Although we measured uterine blood flow in the right uterine artery and total blood flow is the sum of the blood flow to both right and left uterine arteries, the point of hemorrhage was proximal to the branching of both arteries. Hence, the drop in uterine perfusion pressure and consequently blood flow should occur in both uterine arteries; therefore, the decrease shown in our sheep must reflect an overall decrease in uterine blood flow. In the four animals in which blood flow was successfully studied, the right horn of the uterus was the pregnant horn. Thus, although blood flow through the left uterine artery contributes to cotyledonary perfusion, the right uterine artery is likely to have a higher percentage of the total uterine blood flow.

The magnitude of the reduction of uterine blood flow in our study was similar to that of Brinkman et al. (11), who investigated the effects of circulatory shock in an acutely anesthetized sheep preparation by bleeding from a maternal femoral artery. A major difference in the two studies is the fetal status before onset of insult; in a chronic fetal sheep preparation, the fetus is in a stable homeostatic condition before the onset of the insult.

Despite the large volume of blood withdrawn, there was no significant change in central maternal $\mathrm{Hb}$ or hematocrit throughout the study period. Loss of whole blood does not directly result in a decrease in $\mathrm{Hb}$ concentration in the remaining blood without dilution from extravascular fluid. The rapidity with which our hemorrhage was performed probably did not allow for this dilution to occur before our measurements. Furthermore, in the sheep, this dilution is minimized due to the contractile spleen, which attempts to maintain intravascular blood volume.

The main effects on the fetus were hypoxemia, acidemia, a decrease in oxygen content, and an increase in blood flow to the high priority organs. Our findings of fetal hypoxemia were similar to those of Wilkening et al. (6), who demonstrated a reduction in fetal arterial $\mathrm{PO}_{2}$ and oxygen content when uterine blood flow was reduced. The acidosis was both metabolic and respiratory in origin; the respiratory acidosis can be explained by reduced uterine blood flow interfering with carbon dioxide removal from the fetus, whereas the metabolic acidosis suggests that the reduction in uterine blood flow was sufficient to cause fetal hypoxia. Wilkening et al. (6) demonstrated that fetal oxygen consumption and arterial base excess remained within normal limits providing that the amount of oxygen delivered to the fetus exceeds 0.6 $\mathrm{mmol} \cdot \mathrm{min}^{-1} \cdot \mathrm{kg}^{-1}$. Although we did not measure umbilical venous oxygen content, which is necessary to determine oxygen delivery to the fetus, our results may be interpreted to suggest that the reduction in uterine blood flow produced by maternal hemorrhage was below this threshold and hence sufficient to impair fetal oxygen consumption. Brinkman et al. (11) also showed a reduction in uterine oxygen transfer during maternal hypovolemia and that, following a $50 \%$ reduction in maternal blood pressure, the fetus became both hypoxemic and acidemic. Replacement of maternal blood improved and eventually resolved both the respiratory and metabolic acidosis observed during the hypotensive period.

The changes in fetal organ blood flow observed in our study are similar to those found by Cohn et al. (17), who studied the effects of fetal hypoxemia secondary to maternal hypoxia. In our study, there was an increase in blood flow to the brain, heart, and adrenal glands, thereby maintaining oxygen delivery to these high priority organs. In addition, with the exception of the spleen, blood flow to the low priority organs including the kidney, gastrointestinal tract, and carcass was not significantly affected. The most likely explanation for these observations is that the 30-50\% reduction in fetal $\mathrm{PO}_{2}$ and oxygen saturation during maternal hemorrhage was not sufficient to cause a reduction in blood flow to the low priority organs. The fetal hypoxemia achieved in our study secondary to uterine ischemia was not as 
marked as that in the study of Cohn et al. (17), probably contributing to the less pronounced cardiovascular changes in our study.

Blood flow to the fetal organs that showed an increase during uterine ischemia returned to baseline values after maternal blood replacement. These observations suggest that, providing the blood is replaced quickly, fetal circulatory changes produced by maternal uterine bleeding are fully reversible. However, with more prolonged periods of insult, the changes may become irreversible and oxygen delivery to the vital organs may be compromised.

Acknowledgments. The authors thank Dennis Berard and Ann Beauregard for their excellent technical assistance, John Pezzullo, $\mathrm{Ph} . \mathrm{D}$. for the development of the computerized graphics program and graphic preparation, and Mary Arnold for preparation of the manuscript.

\section{REFERENCES}

1. Calvert SA, Hoskins EM, Fong K, Forsyth A 1987 Etiological factors associated with the development of periventricular leukomalacia. Acta Paediatr Scand $76: 254-259$

2. Hurd WW, Miodovnik M, Hertzberg V, Lavin JP 1983 Selective management of abruptio placentae. A prospective study. Obstet Gynecol 61:467-473

3. Paterson MEL 1979 The aetiology and outcome of abruptio placentae. Acta Obstet Gynecol Scand 58:31-35

4. Weindling AM, Wilkinson AR, Cook J, Fok TF, Calvert SA, Rochfort MJ 1985 Perinatal events which precede periventricular haemorrhage and leukomalacia in the newborn. Br J Obstet Gynaecol 92:1218-1223
5. Skillman CA, Plessinger MA, Woods JR, Clark KE 1985 Effect of graded reductions in uterouteroplacental blood flow on the fetal lamb. Am J Physiol 249:H1098-H1105

6. Wilkening RB, Meschia G 1983 Fetal oxygen uptake, oxygenation, and acid base balance as a function of uterine blood flow. Am J Physiol 244:H749H755

7. Yaffe H, Parer JT, Block BS, Llanos AJ 1987 Cardiorespiratory responses to graded reductions of uterine blood flow in the sheep fetus. $J$ Dev Physiol 250:H1037-H1042

8. Anderson DF, Parks CM, Faber JJ $1986 \mathrm{Fetal}_{2}$ consumption in sheep during controlled long-term reductions in umbilical flow on fetal oxygenation. Am J Obstet Gynecol 145:813-818

9. Itskovitz J, Lagamma EF, Rudolph AM 1983 The effect of reducing umbilical flow on fetal oxygenation. Am J Obstet Gynecol 145:813-818

10. Itskovitz J, Lagamma EF, Rudolph AM 1987 Effects of cord compression on fetal blood flow distribution and $\mathrm{O}_{2}$ delivery. Am J Physiol 252:H100- $\mathrm{H} 109$

11. Brinkman CR, Mofid M, Assali NS 1974 Circulatory shock in pregnant sheep. III. Effects of hemorrhage on uterouteroplacental and fetal circulation and oxygenation. Am J Obstet Gynecol 118:77-90

12. Nuwayhid B, Vaughn D, Brinkman III CR, Assali NS 1978 Circulatory shock in pregnant sheep, IV fetal and neonatal circulatory responses to hypovolemia-influence of anesthesia. Am J Obstet Gynecol 132:658-666

13. Berman Jr W, Goodlin RC, Heymann MA, Rudolph AM 1975 Measurement of umbilical blood flow in fetal lambs in utero. J Appl Physiol 39(6):10561059

14. Heymann MA, Payne BD, Hoffman JIE, Rudolph AM 1977 Blood flow measurements with radionuclide labelled particles. Prog Cardiovasc Dis 20:55-79

15. Greiss FC 1966 Uterine vascular response to hemorrhage during pregnancy. Obstet Gynecol 27:549-554

16. Greiss FC 1966 Pressure flow relationship in the gravid uterine vascular bed. Am J Obstet Gynecol 96:41-47

17. Cohn HE, Sacks MA, Heymann MA, Rudolph AM 1974 Cardiovascular responses to hypoxemia and acidemia in fetal lambs. Am J Obstet Gynecol $120: 817-824$ 